\title{
Skeletal Metastatic Carcinoma: A Case from 15th-20th century Coimbra Portugal
}

\begin{tabular}{|r|l|}
\hline Journal: & International Journal of Osteoarchaeology \\
\hline Manuscript ID: & OA-09-0069.R1 \\
\hline Wiley - Manuscript type: & Short Report \\
\hline Author: & \\
\hline Complete List of Authors: & $\begin{array}{l}\text { Wasterlain, Sofia; University of Coimbra, Department of Life } \\
\text { Sciences } \\
\text { Ascenso, Bruna; University of Coimbra, Department of Life Sciences } \\
\text { Silva, Ana Maria; University of Coimbra, Department of Life } \\
\text { Sciences }\end{array}$ \\
\hline Keywords: & Cancer, malignant tumour, metastases, Coimbra, Portugal \\
\hline
\end{tabular}

\section{5 scholarONE \\ Manuscript Central}




\title{
Skeletal Metastatic Carcinoma: A Case from $15^{\text {th }}-20^{\text {th }}$ century Coimbra Portugal
}

\author{
S. N. Wasterlain*; B. F. Ascenso, and A. M. Silva
}

Centro de Investigação em Antropologia e Saúde, Department of Life Sciences

University of Coimbra, 3000 - 056 Coimbra, Portugal

Short title: Skeletal Metastatic Carcinoma from the $15^{\text {th }}-20^{\text {th }}$ century Portugal

\author{
*Correspondence to: Sofia N. Wasterlain, Departamento de Antropologia, Universidade \\ de Coimbra, 3000-056 Coimbra, Portugal \\ Telephone: $351239829051 \quad$ Fax: 351239823491 \\ E-mail address: $\underline{\text { sofiawas @ antrop.uc.pt }}$
}




\begin{abstract}
This paper discusses the differential diagnosis of unusual and distinct pathological changes in the skeletal remains of a +40 year old female from $15^{\text {th }}-20^{\text {th }}$ century Coimbra (Portugal). The most affected area seems to have been the skull, but multiple lesions, lytic and/or blastic, have been found throughout the post-cranial skeleton, more specifically, in the scapulae, clavicles, humerus, sternum, ribs, sacrum, innominates, and femurs. The differential diagnosis of the lesions gave rise to several possible pathological conditions, namely, Langerhans cell histiocytosis (granulomatosis or Histiocytosis X), multiple myeloma, and metastatic carcinoma. Various macroscopic and radiological aspects lead us to consider metastatic carcinoma as the most probable diagnose. Despite the argumentative identity of the possible primary lesion, age, sex and the mixed nature of the osseous response are consistent with cancer of the breast but do not exclude other carcinomas, namely lung cancer. With temporal and regional differences emerging in the frequency of malignant tumours, the identification of new cases becomes important, particularly from geographic areas where few cases have been reported. In fact, the present report adds to the only case of metastatic carcinoma detected in non-identified Portuguese human skeletal remains until now.
\end{abstract}

Key words: Cancer; malignant tumour; metastases; Coimbra; Portugal. 


\section{Case Report}

The remains under analysis were recovered from a cemetery located at Praça do Comércio, Coimbra (Portugal), which dates from the $15^{\text {th }}-20^{\text {th }}$ century. The remains were unearthed in 2002. One incomplete adult individual contains several pathological lesions both in the skull and postcranial skeleton. The exuberant nature and rareness of the lesions as well as the scarcity of reports in the palaeopathological literature, led us to make the differential diagnosis, which we report in this paper.

\section{$\underline{\text { Archaeological background }}$}

In 2002 during repairs to the road surface and plumbing at the Praça do Comércio, Coimbra (Portugal), a cemetery was discovered. During the spring of that year, an archaeological intervention was conducted by the 'Historical Patrimony Centre of Coimbra' (Câmara Municipal de Coimbra). A team from the Department of Anthropology, University of Coimbra, participated in the fieldwork. During the works, nine individual interments, and a sample composed of commingled and scattered skeletal elements were found. The MNI (minimum number of individuals) identified is 61 individuals, including males and females, adults and sub-adults. The methodological procedure employed to obtain the MNI value is described in Silva (1996).

The nine inhumations showed an East-West orientation, with their heads to the West (in accordance to the Christian belief in the resurrection of the soul), except for burial 3 which showed a Northeast-Southwest orientation.

The osteological remains were dated through radiocarbon analysis of the left femur from burial 2 (2 sigma: 1483-1665 cal AD; 1784-1790 cal AD; Sac-1835) and the 
left radius and ulna from burial 9 (2 sigma: 1665-1784 cal AD; 1789-1953 cal AD: Sac-1836).

Among the primary burials, an adult individual showing unusual and distinct pathological changes was isolated. The skeleton was examined by gross inspection, and the bones radiographed through digital mammography (Mamograph General Electrics, senographe DMR, voltage: $30 \mathrm{Kv}$; exposition: $56 \mathrm{mAs}$ ).

\section{The individual}

The individual here described (no. 7) belongs to an adult female. The skull is metopic. Sex determination was made based on the morphology of the skull (Ferembach et al., 1980) and the morphometric analysis of the long bones (Wasterlain, 2000) and hip-bone (Murail et al., 2005). Age of death was assessed as +40 years, based on the degree of closure of the cranial sutures (Masset, 1982) and the appearance of the auricular surface of the ilium (Lovejoy et al., 1985). The stature was estimated in 155.45 $\pm 3.53 \mathrm{~cm}$ (Olivier et al., 1978). The individual was buried in an extended position with her head resting to the left and the upper limbs crossed with the hands over the chest.

\section{$\underline{\text { State of preservation }}$}

The skeleton no. 7 was in a relatively fair condition despite its fragmentary state. The skull, which constitutes one of the pathologically most interesting parts of this specimen, was broken in several pieces and was restored. The restored skull comprises: most of the occipital bone, the almost complete parietal and temporal bones, both bilaterally; a small part of the left greater wing of the sphenoid; the almost complete 
frontal bone, including part of the right orbit; most of both nasal bones; anterior part of the two maxillary bones, and the almost complete mandible.

Most of the available post-cranial bones are incomplete and fragmentary, especially the joint surfaces. The long bones are the best preserved elements. The distal extremities of the lower limb could not be recovered from the field since construction of 20th century water conduit has removed both the tibiae and foot bones.

\section{$\underline{\text { Pathological profile }}$}

Incipient vertebral osteoarthritis was registered in the thoracic and lumbar column. Laminal spurs were recorded in the thoracic vertebrae. Pathological fractures were not found.

All the teeth have been lost during life except the upper canines, which were lost post-mortem. Additionally, a lytic lesion under remodelling is present in relation to the upper right incisors, which have been lost ante-mortem. The alveolar process was already very retracted and atrophic, suggesting that teeth loss occurred a long time prior to death.

\section{Description of the condition}

Several lesions with variable sizes and an irregular shape are apparent in the skull, scapula, clavicles, ribs, sacrum, right innominate, right humerus and both femurs. Some of these lesions are lytic in nature, particularly in the skull, but there are also multiple areas of osteoblastic lesions distributed throughout the post-cranial skeleton. The vertebrae that are present in this specimen show no evidence of significant pathological change, with the exception of the above mentioned degenerative changes. The absence 
of pathological lesions is also true to the sternum, radius, ulna, hand bones and the patallae. As already mentioned, lower limb bones distal to the knees could not be recovered from the field. Details of the lesions observed are presented, according to their locations, in the next sections.

\section{Skull}

Seven defects are apparent in the skull macroscopically. The lesions are asymmetrically distributed and have eroded both tables of the skull but not always to an equal extent. The largest area of destruction, measuring $42 \times 30$ millimetres diameter (all measurements were taken at the greatest diameter of the perforations), affected the frontal bone above the right orbit (Figures 1a,b). Although in this case the outer table of the skull has been more severely eroded than the inner one, occasionally the lesion perforates both tables. Three relatively smaller lytic, but not perforating, lesions are also located on the frontal (two on the left and one on the right side) (Figures 1a,c). Two lesions are located on the right parietal, the largest of which (circa $15 \times 21 \mathrm{~mm}$ ), partly taphonomic, but mainly ante-mortem, completely perforated the bone. Finally, another lytic lesion is located on the occipital bone (10 mm diameter) (Figure 1d). All defects have an irregular outline, with a denticulated edge, formed by external lamina (and sometimes by both external and internal lamina) were dissolved away by the pathological process. In some places, it is apparent that the process was larger in the diploic layer which consists of exposed trabecular bone. This is particularly evident in the largest lesion of the frontal bone. The cortical margins of each of the lytic lesions display some tiny pitting.

The mandible does not show any pathological involvement. 


\section{Scapulae}

The post-mortem destruction of both scapulae made the palaeopathological analysis of bone lesions difficult. However, one fragment of the right scapula displays a layer of new bone deposition $(30 \times 16 \mathrm{~mm})$ close to the lateral border (from a dorsal view). On the left scapula, a less conspicuous bone deposition was visible in the acromial process.

\section{Clavicles}

On the right clavicle (Figure 3a,b) there is one discrete lytic lesion (measuring $3 \mathrm{x}$ 2 millimetres) situated in the superolateral surface. The margins of this osteolytic lesion display a 3-5 $\mathrm{mm}$ perimeter of pitting. Despite the fragmentary state of the laterally adjacent surface, discrete patches of new bone deposition are observable.

Likewise, in the superomedial side of the left clavicle (Figure $3 \mathrm{c}, \mathrm{d}$ ), both pitting and new bone deposits are visible, but a post-mortem fracture led to the loss of the lateral half of the bone, making it impossible to accomplish the paleopathological evaluation.

\section{Ribs}


Twelve rib fragments ( 7 left and 5 right) show very discrete lytic lesions, surrounded, in some cases, by pitting and new bone deposits. This type of alteration presents a bilateral occurrence.

A right rib fragment (Figure 4) displays an osteolytic focus (around $5 \times 4 \mathrm{~mm}$ ), with demarked perforation of the entire shaft. The X-rays of this fragment (Figure 5) reveal more lytic lesions than those which are macroscopically visible. The lesions are associated with some decrease in bone density, presenting irregular and cloudy indistinct margins.

\section{Sacrum}

The sacrum shows a lytic lesion in the $\mathrm{S} 4-5$ segments, with a greater extent on the ventral $(15 \times 11 \mathrm{~mm})$ than on the dorsal $(11 \mathrm{~mm}$ diameter $)$ side. This lesion was minimally enlarged by post-mortem damage.

\section{Hip bones}

On the posterior side of the right ilium, an osteolytic focus penetrated the spongy layer (6 mm diameter) near the greater sciatic notch (Figure 6a,b). Tiny pitting is visible around the margins of the lesion. On a fragment of the right pubis, another lytic lesion, measuring 9 × 6 millimetres, is found (Figure 6c). Once again, the surrounding surface shows pitting and discrete patches of new bone deposition. In the radiograph of the right hip bone (Figure 7), both lesions described macroscopically can be detected. The foci are associated with some decrease in bone density. The edges are ill-defined, not "punched-out". Other changes are seen, but these are possibly due to taphonomic effects. 
The left hip bone does not exhibit pathological alterations.

\section{Humerus}

The right humerus is in a relatively good condition despite the distal end is broken post-mortem (Figure 8). In the proximal diaphysis, on the anteromedial side, cortical bone is perforated by an oval focus $(15 \times 10 \mathrm{~mm}$ diameter, although slightly enlarged by post-mortem damage), leading into the medullar cavity. There are several layers of new bone deposition lining this lytic lesion. In the radiograph of the right humerus (Figure 9), besides the macroscopically described lesion, two further suspicious ill-defined areas of lucidity can be detected in the upper quarter of the shaft, neither of which can be explained by surface phenomena or damage.

The left humerus do not exhibit pathological alterations.

\section{Femurs}

There is evidence of external new bone growth on both femurs. In the right femur, a relatively large osteoblastic lesion $(59 \times 21 \mathrm{~mm})$ is situated on the dorsomedial side of the midshaft (Figures 10a,b).

Radiographic examination of the right femur reveals areas of increased density at the midshaft level (Figure 11).

In the distal shaft of the left femur, on the posterior side, there is a rather large deposition (35 x $20 \mathrm{~mm}$ ) of remodelled coarse subperiosteal bone, with spicules of bone throughout the abnormal area (Figures 12a,b). Proximally to this conspicuous lesion, small deposits of woven bone are visible. In the radiograph of the left femur (Figure 
13), an oval lucid spot with irregular and unclear edges in the distal end of the diaphysis can be found.

\section{Discussion}

The distribution and patterning of the pathological changes here described make metastatic carcinoma the most likely disease affecting skeleton no. 7. However, differential diagnosis against other conditions that mimic metastatic carcinoma, namely Langerhans cell histiocytosis (granulomatosis) and multiple myeloma is necessary.

\section{Langerhans cell histiocytosis (granulomatosis or Histiocytosis X)}

Langerhans cell histiocytosis (originally described as histiocytosis $\mathrm{X}$ by Lichtenstein, 1953) is a systemic inflammatory response of unknown aetiology characterised by malignant histiocytic and dendritic cell proliferation with resulting pathological granular formation (Ortner, 2003c; Marks and Hamilton, 2007). Within the general designation Langerhans cell histiocytosis there are three distinct clinical manifestations: eosinophilic granuloma, Hand-Schüller-Christian disease, and LettererSiwe disease (Ortner, 2003c; Resnick and Kransdorf, 2005b; Marks and Hamilton, 2007). Although the clinical courses of these syndromes are distinct, transitions have been observed and the skeletal lesions are quite similar, both radiologically and histologically. Their distribution may, however, be somewhat different (Ortner, 2003c).

Eosinophilic granuloma represents $70 \%$ of the total number of cases of Langerhans cell histiocytosis. It affects predominantly children, adolescents, or young adults, and occasionally older persons (Ortner, 2003c; Resnick and Kransdorf, 2005b). 
However, when survival beyond early childhood occurs, bone destruction can result in compromised biomechanical integrity and pathological fracture (Ortner, 2003c). Eosinophilic granuloma is more common in men than in women and in whites than in blacks. Solitary lesions are more common than multiple lesions, although multifocal osseous (and extraosseous) disease develops in about $10 \%$ of patients (Resnick and Kransdorf, 2005b). The most frequent sites of involvement are the skull, mandible, spine, ribs, pelvis, and long bones, particularly the femur and humerus. In older individuals, flat bones are more commonly affected than long bones (Resnick and Kransdorf, 2005b). Skull lesions are particularly common in the frontal and parietal bones, and generally present as a solitary, purely lytic, round or oval defect, showing a bevelled edge and, sometimes, a central sequestrum. The involvement of long bones is primarily subcortical, mostly metaphyseal, less commonly mid-diaphyseal, and rarely epiphyseal. If the overlying cortex is destroyed, subperiosteal reactive bone formation occurs. In the long bones, as well as ribs, the lesions can lead to pathological fractures (Ortner, 2003c). Spinal involvement predominates in the thoracic and lumbar regions and the vertebral body localization is most typical (Resnick and Kransdorf, 2005b). Lesions of the vertebral bodies often lead to collapse, creating the appearance of flattened vertebral body, termed vertebra plana, a finding that is more common in children than in adults (Ortner, 2003c; Resnick and Kransdorf, 2005b).

The radiographic manifestations of eosinophilic granuloma vary with its skeletal location. In long bones, the lesions appear as relatively well defined radiolucent areas, particularly in the medullary cavity. As the lesions grow, they encroach on the cortical bone, with endosteal erosion of the cortex and periosteal new bone formation. In the cranial vault, unequal involvement of the tables of the skull gives the margins of the 
lesion a "bevelled edge" appearance. Flat bone lesions may demonstrate a "hole within a hole" appearance" (Resnick and Kransdorf, 2005b). In the mandible, osteolytic lesions can surround the teeth, creating the appearance of "floating teeth" in radiographs (Ortner, 2003c; Resnick and Kransdorf, 2005b). In the pelvis, the lytic lesions may be particularly well defined, with or without surrounding sclerosis (Resnick and Kransdorf, 2005b).

Hand-Schüller-Christian disease can occur in adolescents and young adults, but affects most frequently boys aged 2-5 years old (approximately $2 / 3$ of patients are younger than 5 years) (Aufderheide and Rodríguez-Martín, 1998; Ortner, 2003c; Resnick and Kransdorf, 2005b). The prognosis is variable but can be unfavourable due to the involvement of the brain, pituitary, lungs, or heart. In some cases, spontaneous resolution may occur. It is the most variable of the three syndromes and is characterized by large, multiple, confluent bone lesions that often occur sequentially over several years. In the skull, which is involved in more than $90 \%$ of patients, the lesions are usually devoid of periosteal reactive bone, even after destruction of both tables, although marginal sclerosis of a lytic focus may occur (Ortner, 2003c).

The radiographic manifestations of individual lesions are similar to those of eosinophilic granuloma. In the skull, confluent areas of destruction may isolate islands of bone. In the mandible, radiolucent lesions around the teeth may lead to loss of supporting bone, giving a "floating teeth" appearance (Resnick and Kransdorf, 2005b).

Letterer-Siwe disease is a relatively acute syndrome that is most frequent in infants and children younger than 3 years, although occasional cases were described in late childhood or young adulthood (Ortner, 2003c; Resnick and Kransdorf, 2005b). It involves most organs and tissues of the body, and frequently takes an acute course that 


\section{Multiple myeloma}

Myeloma is a highly malignant, fatal disorder of plasma cells that usually arises in hematopoietic bone marrow. Although it may begin as a single site (solitary plasmacytoma), most frequently moves on quickly to multiple myeloma, or myelomatosis (Rothschild et al., 1998; Ortner, 2003c; Roberts and Manchester, 2005). Its aetiology is unknown but some suggest an abnormality in chromosome 14 (Aufderheide and Rodríguez-Martín, 1998). Multiple myeloma is the most common primary malignant bone tumour today (Gregg et al., 1982). It is rarely found in people below the age of 40 years. In fact, $90 \%$ of cases are found in individuals between the ages of 50 and 60 years (Roberts and Manchester, 2005). Approximately two-thirds of 
the affected persons are male (Aufderheide and Rodríguez-Martín, 1998). The multiple lesions probably arise as independent developments in a systematized neoplastic bone marrow disease, rather than as secondary deposits from a single primary source (Roberts and Manchester, 2005). In decreasing frequency, the following bones are primarily involved: vertebrae, ribs, skull, pelvis, sternum, femur, and humerus. The vertebrae are considered the classic localization of multiple myeloma, the sequence for the other localizations varying with each sample (Alt and Adler, 1992). The lesions are sharply defined holes, varying from 0.5 to $2 \mathrm{~cm}$ in size, though adjacent lesions may coalesce to produce occasional larger ones. Initially they are scattered throughout trabecular bone, becoming most easily visualized radiologically in the flat bones, especially the skull, where both tables may be penetrated. In late stages, the lesions may be so abundant as to have a moth-eaten appearance on the skull X-rays, and long bone metaphyses may be affected (Aufderheide and Rodríguez-Martín, 1998).

The non-specific lesions in multiple myeloma may cause confusion with an osteolytic metastasis from the breast or the thyroid for example (Rothschild et al., 1998; Ortner, 2003b). Multiple myeloma's small rounded/spheroid lesions have sharply localized, discrete edges, surrounded by smooth, unpitted bone, whereas metastases tend to be larger and with more 'ragged' margins (Brothwell, 2008). Sometimes, lesions are described as "being punched out", as if they might have been made by a paperpunch (Morse et al., 1974). Although multiple myeloma can cause osteoblastic response it does not compare with the extent of proliferation seen in osteoplastic metastases from carcinoma (De La Rúa et al., 1995). Besides, according to Strouhal (1991a), lesions of multiple myeloma very commonly involve the mandible, acromion, glenoid and olecranon, scapula, clavicle, radius and ulna, are more widely distributed, and affect 
males more frequently than females. Any evidence of sclerotic bone reaction (except in areas of healing fractures) most probably excludes multiple myeloma.

The large, non-spheroid-shaped, and variable sizes of the lytic cranial lesions here presented, their diffuse radiographic perimeter, the pattern of distribution of the postcranial lesions and also the extent of osteoblastic response did not correspond to the features typical of multiplex myeloma. This diagnosis was therefore excluded.

\section{Metastatic carcinoma}

Metastatic carcinomas primarily develop on the epithelial tissue (Ortner, 2003b). Due to their invasive nature, they are characterised by an uncontrolled proliferation of tumour cells whose dissemination through blood flow, lymphatic nodes and/or cerebrospinal fluid can produce secondary neoplasm focus in other physiological systems, namely the skeleton (Steinbock, 1976; Aufderheide and Rodríguez-Martín, 1998; Ortner, 2003b; Resnick and Kransdorf, 2005a). In fact, bone tissue is one of the most preferred sites for the development of tumour metastasis after lungs and liver (Coleman, 1997; Mundy, 1997; Käkönen and Mundy, 2003). Although it is still not fully understood why certain malignant tumours demonstrate a predilection for bone metastases, the rich vascular network of the skeletal system, particularly the investing vertebral venous plexuses that bathe bone marrow, is probably a strong contributing factor (Marks and Hamilton, 2007). More rarely some primary soft-tissue neoplasms may manifest themselves in bone by virtue of their local bone invasion or by producing enzymes with an ability to resorb system bone (Rosenthal, 1997; Roberts and Manchester, 2005; Schultz et al., 2007). But it must be remembered that death may occur before spread of the cancer to the bones. This would be particularly true for 
ancient human populations, since cancers may have led to death sooner than they do now, because of the way they interfere with vital functions, especially through complications that modern surgical procedures are able to alleviate, thus prolonging life (Capasso, 2005). Other possible reason is that the past socio-hygienic conditions would not allow a lifespan long enough to permit the full development of tumours (Ricci et al., 1994; Weiss, 2000). Additionally, not all cancers have the same tendency to spread to bone. Cancers of the prostate, breast, thyroid gland, kidney, lung, pancreas, testis, bladder and uterus are most likely to produce bone metastases (Waldron, 1996; Coleman, 1997; Mundy, 1997; Rosenthal, 1997; Roberts and Manchester, 2005). These metastases do not tend to be uniformly distributed throughout the skeleton. Although the sites vary between distinct neoplasms, the spine and sacrum, the proximal femoral epiphysis and metaphyses, sternum, ribs, skull, pelvis and proximal humerus are probably the most commonly affected as a consequence of their hematopoietic function as marrow reservoirs (Steinbock, 1976; Waldron, 1996; Mundy, 1997; Aufderheide and Rodríguez-Martín, 1998; Ortner, 2003b; Resnick and Kransdorf, 2005a; Roberts and Manchester, 2005). Skeletal metastases distal to the elbows and knees are apparently rare and do not occur in the fibulae (Steinbock, 1976; Waldron, 1996; Smith, 2002; Ortner, 2003b; Resnick and Kransdorf, 2005a), although cancer of the lung can sometimes present with foot involvement (Marks and Hamilton, 2007). Typically, metastatic tumours affect more than one bone, while solitary lesions on single bones are more characteristic of renal or thyroid carcinomas (Ortner, 2003b).

The tumour cells destroy the marrow, followed by destruction of bone, and sometimes formation (Roberts and Manchester, 2005). In fact, of metastatic tumours to bone $75 \%$ are osteolytic, $15 \%$ are osteoblastic, and $10 \%$ are mixed osteolytic and 
osteoblastic (Ortner, 2003b). Bone destruction is usually the result of cancer of the lung, breast, gastrointestinal tract, thyroid gland and kidney, while bone-forming lesions are caused by prostate cancer in males and cancer of the breast, uterus and ovary in females. Mixed lesions are most common in carcinoma of the lung and breast (Coleman, 1997; Aufderheide and Rodríguez-Martín, 1998; Ortner, 2003b; Resnick and Kransdorf, 2005a).

The lytic cranial lesions associated with metastatic carcinoma are among the most conspicuous pathological alterations seen in archaeological samples. The lesions are typically multiple, variably sized with a likely scalloped or denticulated, even slightly elevated perimeter (Waldron, 1987; Strouhal, 1991a; Marks and Hamilton, 2007). The area of transition between the osteoclastic process and normal bone is characterized by pitting (Smith, 2002). Radiographically, this commonly appears as a discrete radiolucency surrounded by a cloudy or 'moth-eaten' perimeter (Strouhal, 1991a). As metastases may not always be visible on direct inspection, it is likely that more are found when X-rays are performed (Waldron, 1997).

Osteoblastic lesions in dry bone may present as excrescent coarse fibre bone or speculated overgrowth. Radiographically, the new bone deposits are presented as opacities or 'blotchy' densities. There is, however, considerable diagnostic overlap with osteomyelitis or periostitis (Smith, 2002).

Bone metastases are particularly frequent in individuals above 40 (Melikian, 2006), and according to Strouhal (1991a), can be expected to occur more commonly in females, especially due to longer lasting breast cancer, which did not threaten life in past populations as much as cancers of vital organs. 
Clinically, bone metastases cause considerable morbidity, including pain, impaired mobility, hypercalcemia, pathologic fracture after trivial injury, spinal cord or nerve root compression, and bone marrow infiltration (Coleman, 1997; Mundy, 1997). It also signifies that the malignant process is no longer curable and, even nowadays, only palliative therapy is available (Mundy, 1997).

The present case exhibited many of the morphological and radiographic features of a metastatic carcinoma. The multifocal character of the lesions (their large number, varying dimensions, asymmetrical shape, rough edges, the mixed nature of the osseous response, and the anatomical distribution of the lesions, which spared the distal parts of the extremities from the elbows) permits a diagnosis. Radiographs of the cranium, right humerus, left femur, and one right rib, reveal more lytic lesions than those which are macroscopically visible. In the long bones (right humerus and left femur), the occult lesions are located in the shaft, close to the metaphyseal regions. The rich supply of haematogenous tissue of these anatomical areas may have influenced the development of these new metastatic foci in progress at death, not visible under macroscopic analysis. Almost all lesions are associated with some decrease in bone density and all present cloudy indistinct margins. The only exception is the X-ray of the right femur, which reveals areas of increased density at the midshaft level. According to the palaeopathological literature, periosteal reaction as well as radiographically evident thickening of the long bones at midshaft such as that seen on the right femur of individual no. 7 is consequential to the carcinomatous process (Smith, 2002; Ortner, 2003b). 
Both the morphological and radiological characteristics of the skeletal lesions here presented resemble those seen in other archaeological cases differentially diagnosed as likely metastatic carcinoma (Marcsik et al., 2002; Smith, 2002).

Although, it is frequently impossible to determine the source of the primary tumour, the age and female sex of the individual as well as the mixed nature of the osseous response favour a carcinoma with a probable location in the breast. In fact, the breast is the most common site of origin for metastases affecting the skeleton in modern women. Other carcinomas (e.g. lung cancer, carcinoma of the colon and rectum) also readily metastize to bone, produce lytic or mixed osteolytic-osteosclerotic lesions, and cannot be excluded. However, breast tumours are believed to have been more frequent than lung cancer in the past (Melikian, 2006). Even nowadays, patients with disseminated breast carcinoma may live longer and are more likely to develop bone metastases than individuals with lung cancer who have a much shorter life expectancy (Käkönen and Mundy, 2003).

\section{Conclusions}

We are quite sensitive to the fact that differential diagnosis in osteological materials is limited due to the absence of clinical diagnostic attributes (Ortner, 2003a). We are also aware of the importance of performing a histological analysis of the lesions to give a more confident diagnosis. While differential diagnosis of primary neoplasm is not always problematic, there is a great deal of difficulty in differentiating between secondary tumours sometimes caused by rather different agents (e.g. multiple myeloma versus osteolytic metastases) (De La Rúa et al., 1995). Even so, the multiple non- 
spheroid-shaped and variable sized bone lesions as well as their locations suggest that this +40 year old female from the $15^{\text {th }}-20^{\text {th }}$ century Coimbra (Portugal) had metastatic carcinoma. Despite the argumentative identity of the possible primary lesion, age, sex and the mixed nature of the osseous response are consistent with cancer of the breast but do not exclude other carcinomas, namely lung cancer and carcinoma of the colon and rectum.

In view of the scarcity with which cancer metastases, particularly those with both lytic and blastic components, have been diagnosed in archaeological specimens in general, and considering the temporal and regional differences emerging in the frequencies of malignant tumours (Strouhal, 2000), it is important to report all new cases which are discovered. As pointed out by several authors (Strouhal, 1991b; Marks and Hamilton, 2007), accurate identification of all examples of cancer in antiquity represents an important contribution to paleopathology in light of the increasing clinical, epidemiological and demographic importance of this disease today. Certain types of cancer that are thought to be characteristic of our own times and frequently described as being due to our western civilization are also found in ancient populations (Schultz et al., 2007). Recently, a first case of malignant carcinoma was described in non-identified Portuguese human skeletal remains (Assis and Codinha, 2009). Therefore, the present case adds to the only archaeological case description available for metastatic carcinoma in Portugal.

\section{Acknowledgements}


The authors would like to thank Câmara Municipal de Coimbra, and Centro de Investigação em Antropologia e Saúde. The authors are also grateful to the Clínica Universitária de Imagiologia dos Hospitais da Universidade de Coimbra for producing the radiographs of the bones. The authors also acknowledge the editor of the journal and the anonymous reviewers whose valuable comments and suggestions allowed us to improve the manuscript.

\section{References}

Alt KW, Adler C-P. 1992. Multiple myeloma in an Early Medieval skeleton. Int J Osteoarchaeol 2: 205-209.

Assis S, Codinha S. 2009. Metastatic carcinoma in a $14^{\text {th }}-19^{\text {th }}$ century skeleton from Constância (Portugal). Int J Osteoarchaeol DOI: 10.1002/oa (in press).

Aufderheide AC, Rodríguez-Martín C. 1998. The Cambridge encyclopedia of human paleopathology. Cambridge University Press: Cambridge.

Brothwell D. 2008. Tumours and tumour-like processes. In Advances in human palaeopathology, Pinhasi R, Mays S (eds.). John Wiley \& Sons: Chichester; 253281.

Capasso LL. 2005. Antiquity of cancer. Int J Cancer 113: 2-13. DOI: 10.1002/ijc. 20610

Coleman RE. 1997. Skeletal complications of malignancy. Cancer 80: 1588-1594. 
De La Rúa C, Baraybar JP, Etxeberria F. 1995. Neolithic case of metastasizing carcinoma: multiple approaches to differential diagnosis. Int J Osteoarchaeol 5: 254-264.

Ferembach D, Schwidetzky I, Stloukal M. 1980. Recommendations for age and sex diagnosis of skeletons. J Hum Evol 9: 517-550.

Gregg JB, Steele JP, Bass WM. 1982. Unusual osteolytic defects in ancient South Dakota skulls. Am J Phys Anthropol 58: 243-254.

Käkönen S-M, Mundy GR. 2003. Mechanisms of osteolytic bone metastases in breast carcinoma. Cancer 97: 834-839. DOI: 10.1002/cncr.11132

Lichtenstein L. 1953. Histiocytosis X: integration of eosinophilic granuloma of bone, "Letterer-Siwe disease," and "Schüller-Christian disease" as related manifestations of a single nosologic entity. Arch Pathol 56: 84-102.

Lovejoy C, Meindl R, Pryzbeck T, Mensforth R. 1985. Chronological metamorphosis of the auricular surface of the ilium: a new method for the determination of adult skeletal age at death. Am J Phys Anthropol 68: 15-28.

Marcsik A, Szathmáry L, Finnegan M. 2002. Multiple myeloma and metastatic skeletal lesions in osteoarchaeology samples. J Paleopathol 14: 77-86.

Marks MK, Hamilton MD. 2007. Metastatic carcinoma: palaeopathology and differential diagnosis. Int J Osteoarchaeol 17: 217-234. DOI: 10.1002/oa.874

Masset C. 1982. Estimation de l'âge au décès par les sutures crâniennes. Thèse de Doctorat. Université Paris VII: Paris.

Melikian M. 2006. A case of metastatic carcinoma from $18^{\text {th }}$ century London. Int $J$ Osteoarchaeol 16: 138-144. DOI: 10.1002/oa.813 
Morse D, Dailey RC, Bunn J. 1974. Prehistoric multiple myeloma. Bulletin of the New York Academy of Medicine 50 (4): 447-458.

Mundy GR. 1997. Mechanisms of bone metastasis. Cancer 80: 1546-1556.

Murail P, Bruzek J, Houët F, Cunha E. 2005. Dsp: a tool for probabilistic sex diagnosis using worldwide variability in hip-bone measurements. Bulletins et Mémoires de la Société d'Anthropologie de Paris, n.s., 17 (3-4): 167-176.

Olivier G, Aaron C, Fully G, Tissier G. 1978. New estimations of statures and cranial capacity in modern man. J Hum Evol 7: 513-518.

Ortner DJ. 2003a. Background data in paleopathology. In Identification of pathological conditions in human skeletal remains, Ortner DJ (ed.). $2^{\text {nd }}$ Edition. Academic Press: San Diego; 37-44.

Ortner DJ. 2003b. Tumours and tumour-like lesions of bone. In Identification of pathological conditions in human skeletal remains, Ortner DJ (ed.). $2^{\text {nd }}$ Edition. Academic Press: San Diego; 503-544.

Ortner DJ. 2003c. Reticuloendothelial and hematopoietic disorders. In Identification of pathological conditions in human skeletal remains, Ortner DJ (ed.). $2^{\text {nd }}$ Edition. Academic Press: San Diego; 359-382.

Resnick D, Kransdorf MJ. 2005a. Skeletal metastasis. In Bone and Joint Imaging, Resnick D, Kransdorf MJ (eds.). $3^{\text {rd }}$ Edition. Elsevier Saunders Inc: Philadelphia; $1245-1264$.

Resnick D, Kransdorf MJ. 2005b. Lipidoses, histiocytosis, and hyperlipoproteinemias. In Bone and Joint Imaging, Resnick D, Kransdorf MJ (eds.). $3^{\text {rd }}$ Edition. Elsevier Saunders Inc: Philadelphia; 665-684. 
Ricci R, Lama, R, Di Tota G, Pietrangelo F, Vecchio FM, Evangelista A, Capelli A, Capasso, L. 1994. Skull osteolytic lesions in a XV century child: a case of childhood malignancy. J Paleopathol 6: 151-159.

Roberts C, Manchester K. 2005. The archaeology of disease. $3^{\text {rd }}$ Edition. Sutton Publishing Limited: Gloucestershire.

Rosenthal DI. 1997. Radiologic diagnosis of bone metastases. Cancer 80: 1595-1607.

Rothschild BM, Hershkovitz I, Dutour O. 1998. Clues potentially distinguishing lytic lesions of multiple myeloma from those of metastatic carcinoma. Am J Phys Anthropol 105: 241-250.

Schultz M, Parzinger H, Posdnjakov DV, Chikisheva TA, Schmidt-Schultz TH. 2007. Oldest known case of metastasizing prostate carcinoma diagnosed in the skeleton of a 2,700-year-old Scythian king from Arzhan (Siberia, Russia). Int J Cancer 121: 2591-2595. DOI: 10.1002/ijc.23073

Silva AM. 1996. O Hipogeu de Monte Canelas I (IV-III milénios A. C.): estudo paleobiológico da população humana exumada. Graduation thesis. Departament of Anthropology, University of Coimbra: Coimbra. (Unpublished)

Smith MO. 2002. A probable case of metastatic carcinoma from the late prehistoric Eastern Tennessee River Valey. Int $J$ Osteoarchaeol 12: 235-247. DOI: $10.1002 /$ oa. 618

Steinbock R. 1976. Paleopathological diagnosis and interpretation: bone diseases in ancient human populations. Charles C. Thomas: New York.

Strouhal E. 1991a. Myeloma multiplex versus osteolytic metastatic carcinoma: differential diagnosis in dry bones. Int J Osteoarchaeol 1: 219-224. 
Strouhal E. 1991b. A case of primary carcinoma from Christian Sayala (Egyptian Nubia). J Paleopathol 3: 151-166.

Strouhal E. 2000. Malignant tumours of past populations in middle Europe. Lecture given at the $13^{\text {th }}$ European Meeting of the Paleopathology Association, Chieti, Italy (abstract).

Waldron T. 1987. Lytic lesions in a skull: a problem in diagnosis. J Paleopathol 1: 514.

Waldron T. 1996. What was the prevalence of malignant disease in the past? Int $J$ Osteoarchaeol 6: 463-470.

Waldron T. 1997. A nineteenth-century case of carcinoma of the prostate, with a note on the early history of the disease. Int J Osteoarchaeol 7: 241-247.

Wasterlain SN. 2000. Morphé: análise das proporções entre os membros, dimorfismo sexual e estatura de uma amostra da Colecção de Esqueletos Identificados do Museu Antropológico da Universidade de Coimbra. Masters Dissertation on Human Evolution. Departament of Anthropology, University of Coimbra: Coimbra.

Weiss L. 2000. 1. Observations on the antiquity of cancer and metastasis. Cancer and Metastasis Reviews 19: 193-204. 


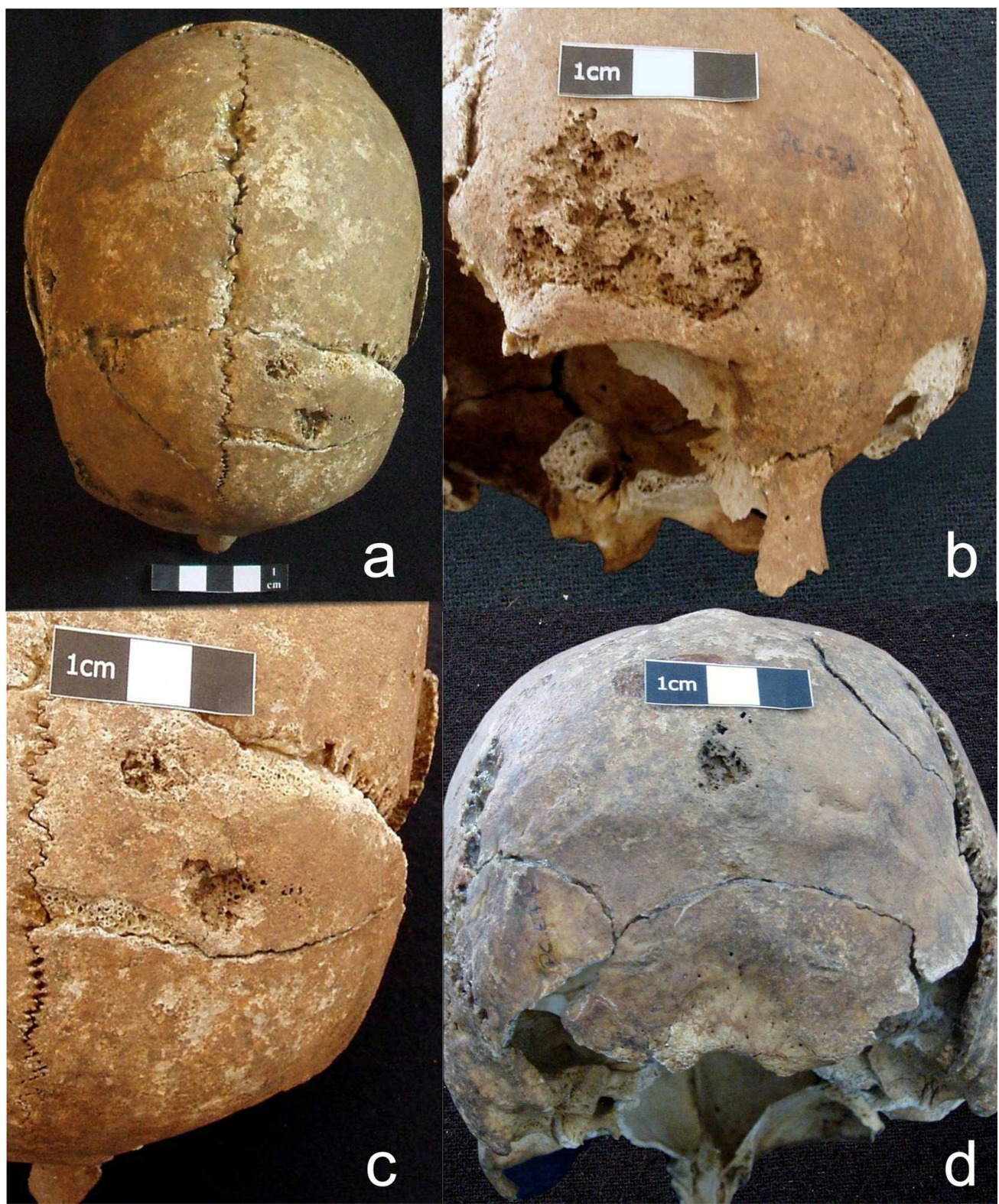

Figure 1: The osteolytic changes to the cranium of the individual no.7 from Praça do Comércio (Coimbra, Portugal). Superior view (a) of four primary lytic lesions. Right frontal bone (b) with a large osteolytic lesion. Two smaller non-perforating foci (c) are located on the left frontal bone. One osteolytic lesion (d) is seen in the central occipital bone. $140 \times 168 \mathrm{~mm}(300 \times 300 \mathrm{DPI})$ 


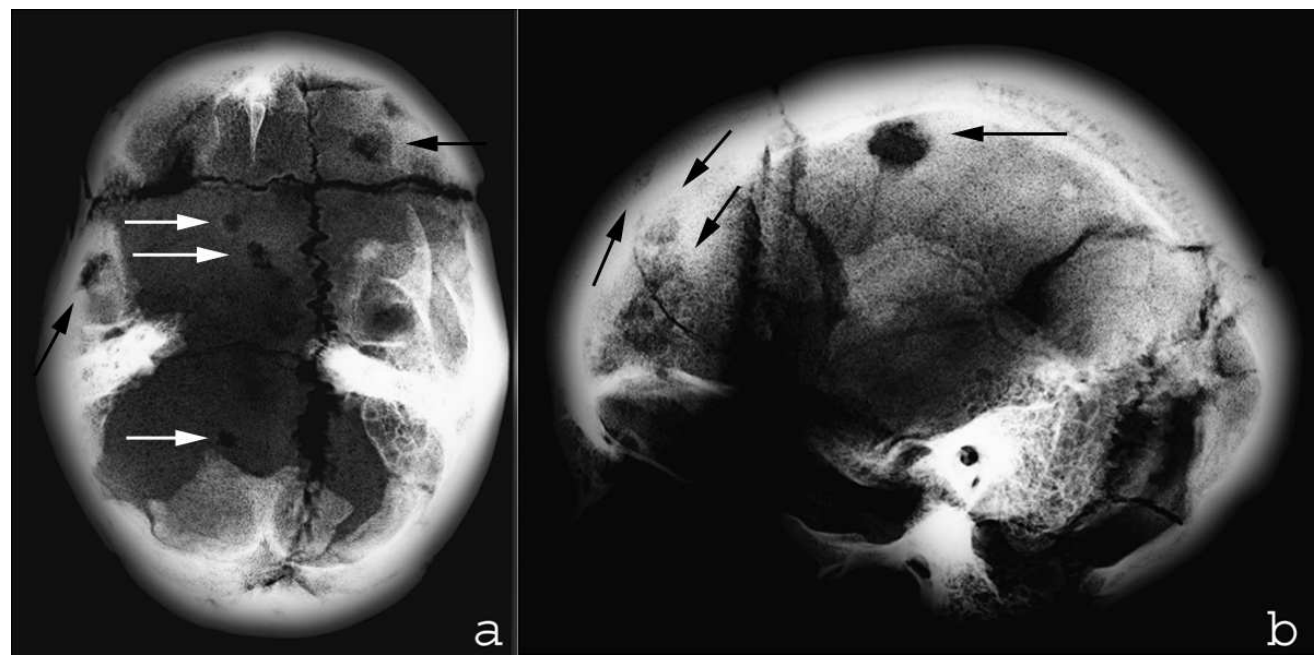

Figure 2: Inferior (a) and lateral (b) radiographs of the cranium of the individual no.7 from Praça do Comércio (Coimbra, Portugal), revealing three more lytic lesions (white arrows) than those which are macroscopically visible (black arrows). The lesions are associated with some decrease in bone density and all present cloudy indistinct margins. $100 \times 50 \mathrm{~mm}(300 \times 300$ DPI $)$ 


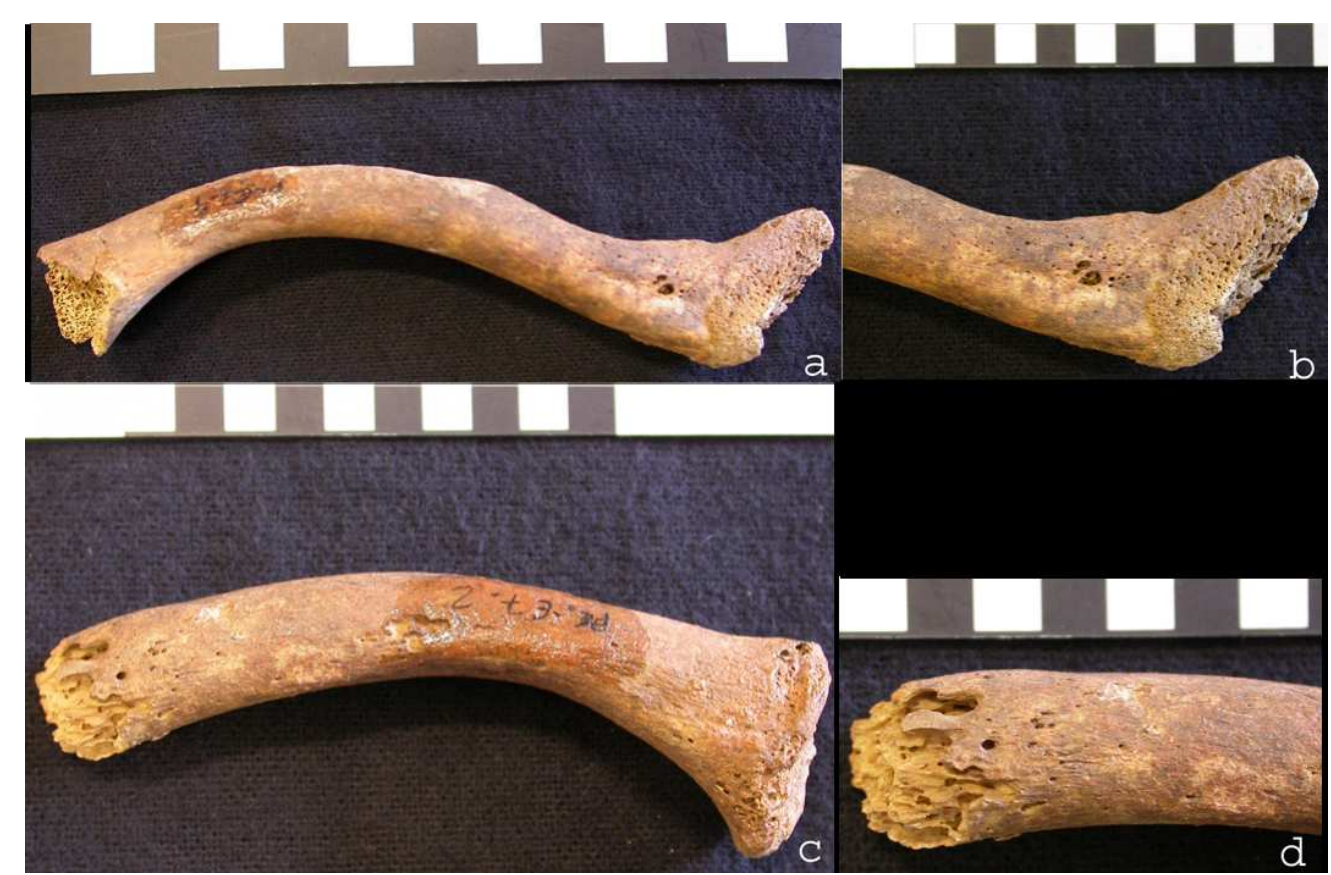

Figure 3: View of the right ( $a, b)$ and left $(c, d)$ clavicles of the individual no.7 from Praça do Comércio (Coimbra, Portugal). On the right clavicle $(a, b)$ there is one discrete lytic lesion situated in the superolateral surface, surrounded by pitting. In the superomedial side of the left clavicle (c, d), both pitting and new bone deposits are visible. $90 \times 58 \mathrm{~mm}(300 \times 300 \mathrm{DPI})$ 


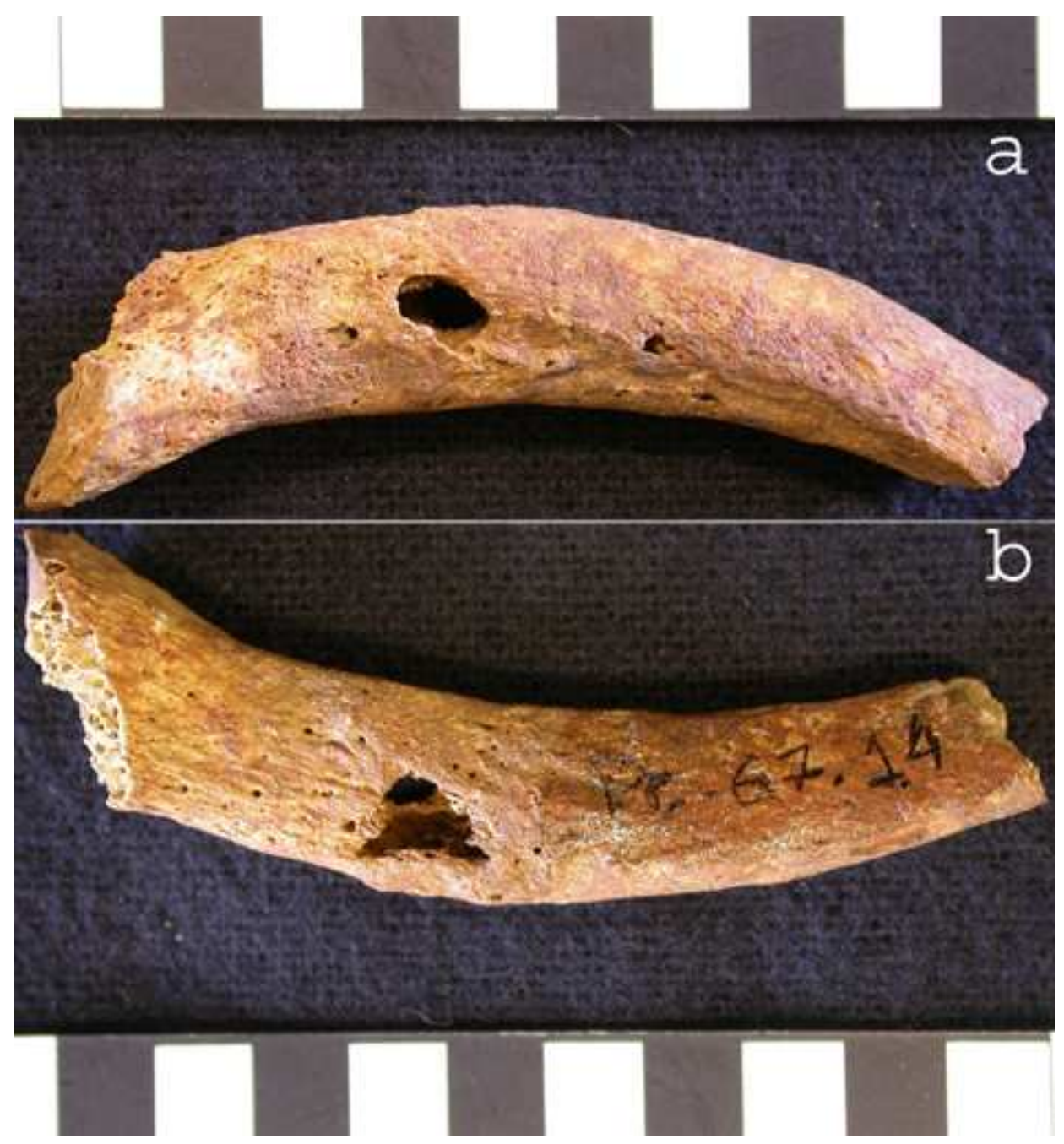

Figure 4: Posterior (a) and visceral (b) views of one right rib fragment belonging to the individual no.7 from Praça do Comércio (Coimbra, Portugal). The osteolytic focus perforates the entire shaft. $40 \times 43 \mathrm{~mm}(300 \times 300 \mathrm{DPI})$ 
Figure 5: Radiograph of the right rib fragment which reveals more lytic lesions than those which are macroscopically visible [Praça do Comércio (Coimbra, Portugal), individual no.7]. $39 \times 14 \mathrm{~mm}(300 \times 300$ DPI $)$ 


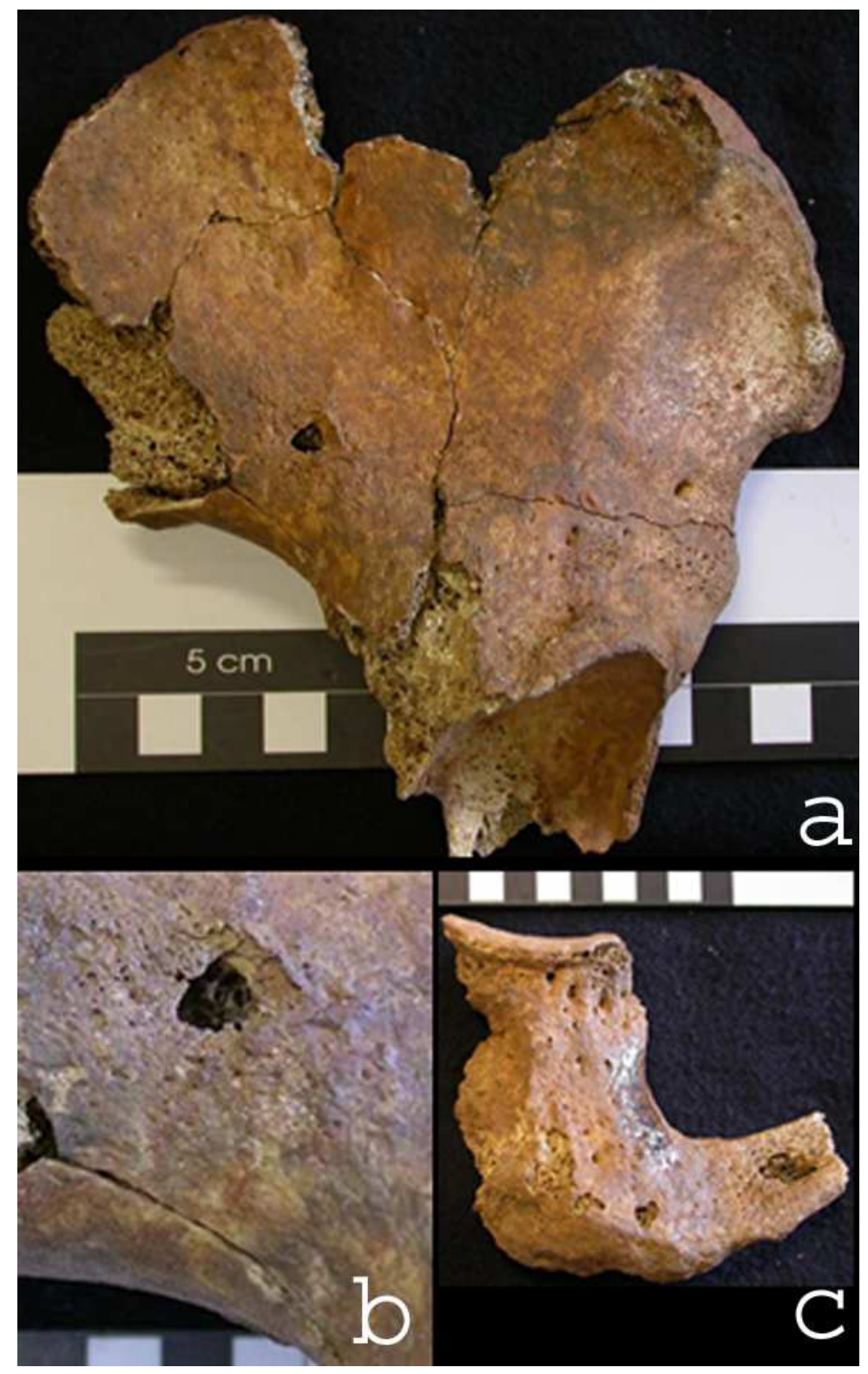

Figure 6: Posterior view (a) of the right hip bone of the individual no.7 from Praça do Comércio (Coimbra, Portugal). Note an osteolytic cavity near the great sciatic notch. Close up of the lesion (b). Fragment of the right pubis (c) displaying another lytic lesion. $50 \times 80 \mathrm{~mm}(300 \times 300 \mathrm{DPI})$ 


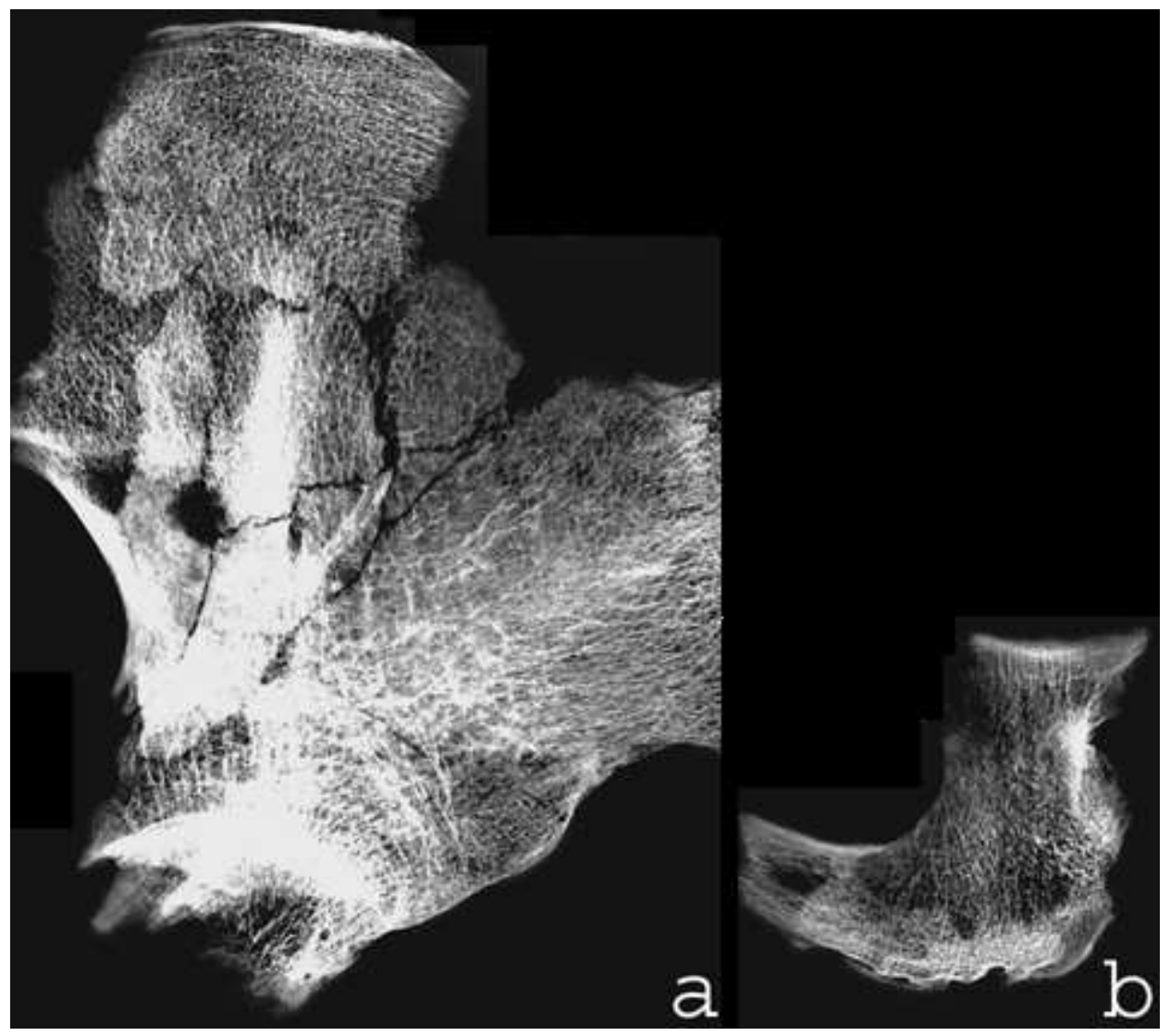

Figure 7: Radiography of the fragmented right hip bone (a) and tuber ischiadicum (b) of the individual no.7 from Praça do Comércio (Coimbra, Portugal). All lesions described macroscopically can be detected. The foci are associated with some decrease in bone density and their edges are illdefined. Other changes are seen, but these are possibly due to taphonomic effects. $40 \times 35 \mathrm{~mm}(300 \times 300$ DPI $)$ 


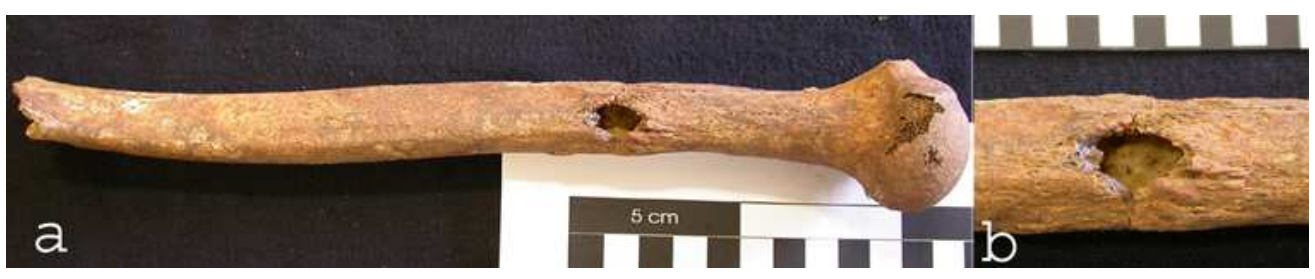

Figure 8: Medial view (a) of the right humerus of the individual no.7 from Praça do Comércio (Coimbra, Portugal), showing a relatively large and oval destructive focus leading into the medullar cavity. Close up of the lesion (b). $64 \times 12 \mathrm{~mm}(300 \times 300 \mathrm{DPI})$ 
Figure 9: Radiograph of the right humerus of the individual no.7 from Praça do Comércio (Coimbra, Portugal). Besides the macroscopically described lesion, two further suspicious ill-defined areas of lucidity can be detected in the upper quarter of the shaft, neither of which can be explained by surface phenomena or damage. $99 \times 22 \mathrm{~mm}(300 \times 300$ DPI $)$ 
Figure 10: Posterior view of the right femur (a) of the individual no.7 from Praça do Comércio (Coimbra, Portugal, ) showing a relatively large osteoblastic lesion situated on the dorsomedial side of the midshaft. Close up of the lesion (b). $119 \times 21 \mathrm{~mm}(300 \times 300 \mathrm{DPI})$ 
Figure 11: Radiography of the right femur of the individual no.7 from Praça do Comércio (Coimbra, Portugal) showing a destructive focus at the midshaft level, surrounded by an area of increased density.

$99 \times 20 \mathrm{~mm}(300 \times 300 \mathrm{DPI})$ 
Figure 12: Posterior view (a) of the left femur of the individual no.7 from Praça do Comércio (Coimbra, Portugal) with new bone deposition near the distal extremity. Close up of the lesion (b). $119 \times 22 \mathrm{~mm}(300 \times 300 \mathrm{DPI})$ 
Figure13: Radiography of the left femur of the individual no.7 from Praça do Comércio (Coimbra, Portugal) showing an oval lucid spot with irregular and unclear edges in the distal end of the diaphysis, which is not apparent macroscopically. $99 \times 28 \mathrm{~mm}(300 \times 300 \mathrm{DPI})$ 